\title{
BMJ Open Multimorbidity prevalence and pattern in Indonesian adults: an exploratory study using national survey data
}

\author{
Mohammad Akhtar Hussain, ${ }^{1}$ Rachel R Huxley, ${ }^{2}$ Abdullah Al Mamun ${ }^{1}$
}

\begin{abstract}
To cite: Hussain MA, Huxley RR, Al Mamun A. Multimorbidity prevalence and pattern in Indonesian adults: an exploratory study using national survey data. BMJ Open 2015;5:e009810. doi:10.1136/bmjopen-2015009810
\end{abstract}

- Prepublication history and additional material is available. To view please visit the journal (http://dx.doi.org/ 10.1136/bmjopen-2015009810).

Received 24 August 2015 Revised 2 November 2015 Accepted 3 November 2015

CrossMark

\footnotetext{
${ }^{1}$ Division of Epidemiology and Biostatistics, School of Public Health, The University of Queensland, Brisbane, Queensland, Australia ${ }^{2}$ School of Public Health, Curtin University, Perth, Western Australia, Australia
}

Correspondence to Dr Mohammad Akhtar Hussain;

drakhtarhussain@gmail.com

\section{ABSTRACT}

Objectives: To estimate the prevalence and pattern of multimorbidity in the Indonesian adult population.

Design: Cross-sectional study.

Setting: Community-based survey. The sampling frame was based on households in 13 of the 27 Indonesian provinces, representing about $83 \%$ of the Indonesian population.

Participants: 9438 Indonesian adults aged 40 years and above.

Main outcome measures: Prevalence and pattern of multimorbidity by age, gender and socioeconomic status.

Results: The mean number of morbidities in the sample was 1.27 (SE \pm 0.01$)$. The overall age and sex standardised prevalence of multimorbidity was $35.7 \%$ (34.8\% to $36.7 \%$ ), with women having significantly higher prevalence of multimorbidity than men $(41.5 \%$ vs $29.5 \% ; p<0.001)$. Of those with multimorbidity, $64.6 \%(62.8 \%$ to $66.3 \%)$ were aged less than 60 years. Prevalence of multimorbidity was positively associated with age $\left(\mathrm{p}_{\text {for trend }}<0.001\right)$ and affluence $\left(p_{\text {for trend }}<0.001\right)$ and significantly greater in women at all ages compared with men. For each 5-year increment in age there was an approximate $20 \%$ greater risk of multimorbidity in both sexes $(18 \%$ in women $95 \% \mathrm{Cl} 1.14$ to 1.22 and $22 \%$ in men $95 \% \mathrm{Cl}$ 1.18 to 1.26$)$. Increasing age, female gender, nonJavanese ethnicity, and high per-capital expenditure were all significantly associated with higher odds of multimorbidity. The combination of hypertension with cardiac diseases, hypercholesterolemia, arthritis, and uric acid/gout were the most commonly occurring disease pairs in both sexes.

Conclusions: More than one-third of the Indonesian adult population are living with multimorbidity with women and the more wealthy being particularly affected. Of especial concern was the high prevalence of multimorbidity among younger individuals. Hypertension was the most frequently occurring condition common to most individuals with multimorbidity.

\section{INTRODUCTION}

Multimorbidity, the simultaneous existence of two or more chronic health conditions

\section{Strengths and limitations of this study}

- This is the first study to examine the prevalence, pattern and socioeconomic correlates of multimorbidity among Indonesian adults using data from a large representative cross-sectional survey.

- In addition to informing on prevalence of morbidity we examined the age and gender patterns associated with the most frequently occurring combinations of chronic morbid conditions.

- Limitations of the study are the use of selfreported data and the restriction to a predefined set of morbidities.

- The cross-sectional nature of the study precluded any causal inference from being made.

within an individual, without a defining primary index disease, is increasingly becoming the norm rather than the exception, particularly in high-income countries. ${ }^{1-3}$ It increases progressively with age, ${ }^{2}{ }^{4}$ and is associated with increased risk of premature mortality and reduced quality of life. ${ }^{5}$ In addition to these significant individual-level issues, multimorbidity is associated with substantial societal costs due to increased healthcare utilisation, and the greater demands on the healthcare system that it creates. ${ }^{6-10}$ Furthermore, the pharmacomanagement of multimorbidity is multifaceted, often requiring polypharmacy that in turn is associated with high rates of adverse complications. ${ }^{8}{ }^{11}$ Moreover, its clinical management is complex and in practice, hindered by the lack of specific guidelines for the management of patients with multiple chronic conditions. $^{12}$

Previously, the study of the burden of multimorbidity has largely been confined to developed countries due to the availability of relevant data with which to examine this issue. ${ }^{13}$ However, there is increasing recognition that the burden of multimorbidity is of increasing importance to populations in lower and middle-income countries. 
Historically, the pattern of mortality in these countries has largely been dominated by communicable diseases; but, substantive successes in public health over the past several decades in these countries has led not only to marked gains in life expectancy but an increase in the prevalence of chronic conditions placing additional strain on healthcare systems that are ill-equipped for coping with the growing widespread demand for chronic disease care. ${ }^{13-17}$

Indonesia, the world's fourth most populous nation, is in the midst of a profound demographic and epidemiological transition. ${ }^{18}$ Recent studies have identified Indonesia's sizeable chronic disease burden but little is known regarding the pattern of multimorbidity in the population. ${ }^{19}$ Although Indonesia has an extensive primary healthcare structure that is largely delivered through a network of community health centres (Puskesmas), auxiliary health centres (Pustu) and private medical practice, recent evidence suggests that the country has limited capacity in its public health system to cope with any further increases in healthcare demand. ${ }^{20}$ The purpose of the current study is therefore to inform on the prevalence, patterns and risk factors associated with multimorbidity in the Indonesian population; such information is a vital pre-requisite for the design and implementation of an effective primary healthcare system that is capable of delivering a comprehensive continuum of care to patients with multiple morbidities.

\section{METHODS}

\section{Data source}

Data for this study are from the fourth wave of Indonesian Family Life Survey (IFLS-4). IFLS is an ongoing health and socioeconomic comprehensive longitudinal survey consisting of four waves, beginning in 1993 and collected information on individual, household and community level. The original sampling frame was based on households in 13 of the 27 Indonesian provinces, representing about $83 \%$ of the Indonesian population in $1993 .{ }^{21}$ Briefly, IFLS-1 collected information from over 22000 individuals living in 7224 households. These original households and their split-offs were followed in subsequent waves fielded in 1997/1998, 2000 and $2007 / 2008$. The recontact rates for the target households were more than $90 \%$ in all follow-up surveys. Moreover, in IFLS-4, 90.6\% of target households were successfully recontacted with the lowest recontact rate in Jakarta $(80.3 \%)$. The fourth wave of the survey included 44103 (51.0\% female) individuals from 13535 households from urban and rural locations. ${ }^{21}$ The sampling and survey methods for the IFLS have been discussed in detail elsewhere. ${ }^{21}$ The IFLS-4 data are open for public use after registration on their website (http://www.rand. org/labor/FLS/IFLS/ifls4.html). IFLS-4 collected individual-level data on anthropometry, morbidity indicators, healthcare utilisation, health behaviours and household expenditure as well as information on questions related to chronic morbid conditions in participants aged 40 years and above. Hence, this analysis is limited to that age-group.

\section{Measurements}

For our analysis, multimorbidity was the primary outcome measure and was defined as the presence of two or more chronic conditions in individual respondents. ${ }^{1} 278$ The individual morbidity status was ascertained either through active measurements, or through self-report or both. Active measurements were obtained by a qualified team of trained nurses for biophysical parameters namely anthropometry, blood pressure (BP) and total cholesterol levels. ${ }^{21}$ Three BP measurements were obtained using Omron self-inflating sphygmomanometers with a digital read-out and total cholesterol was measured using Cardiochek PA system. ${ }^{21}$ To determine the occurrence of self-reported chronic conditions respondents were asked the question "Has a doctor/ paramedic/nurse/midwife ever told you that you had following chronic conditions of diseases?" with response options: hypertension, diabetes, tuberculosis, asthma and other chronic lung diseases, cardiac diseases(heart attack/coronary heart disease/angina or other heart diseases), liver diseases, stroke, cancer or malignancies, arthritis/rheumatism, uric acid/gout, depression, vision and hearing abnormalities. Among respondents with no reported diabetes or heart problems, undiagnosed diabetes and heart problems were identified based on the number of affirmative responses to conditions symptomatic of the respective disease. ${ }^{22}$ For diabetes, these were: (1) often wake up to urinate during the night, (2) a cut or wound takes a long time to heal and (3) often have headache when waking up in the morning. For heart problems, these were (1) ever felt pain on the left side of your chest, (2) ever felt chest pains when climbing upstairs or uphill, and (3) ever felt chest pains when being active or walking fast. Undiagnosed diabetes was defined as having all three symptoms; undiagnosed heart problem was defined as having at least two symptoms. Beside self-reported depression, presence of depression was quantitatively measured using a short version of the Centre for Epidemiologic Studies Depression Scale (CES-D); a series of 10 questions examining depression symptoms. In this study, the CES-D score was treated as a dichotomous categorical variable with a score of equal to or greater than 11 representing significant depressive symptoms. ${ }^{23}$ Participants with a positive history of asthma and other chronic lung diseases were defined as having a chronic respiratory disease, while arthritis and rheumatism were grouped together as arthritis.

For this analysis, we included obesity (body mass index (BMI) $\geq 30 \mathrm{~kg} / \mathrm{m}^{2}$ ) and hypercholesterolemia (blood total cholesterol value $>6.2 \mathrm{mmol} / \mathrm{L}$ as additional chronic morbidities based on anthropometric and biochemical measurements. Hypertensive status was 
ascertained based on self-report and the mean BP value of three measurements. Respondents were classified as hypertensive if they had a mean systolic BP $\geq 140 \mathrm{~mm} \mathrm{Hg}$ and/or mean diastolic $\mathrm{BP} \geq 90 \mathrm{~mm} \mathrm{Hg}$, or were currently taking hypertension medication. ${ }^{24}$

Sociodemographic factors as individual level determinants were based on self-report and included age, gender, ethnicity (Javanese, non-Javanese), household location (urban, rural), marital status(currently married, currently not married including unmarried, separated or divorced and widow(er)), education level (elementary education or less, high school completed, graduate and above), participants economic status (per capita expenditure for consumption). Per capita expenditure, the measure of current or 'immediate' living standard rather than income, was considered as economic status due to the fact that expenditure is the preferred direct measure of welfare in developing countries. ${ }^{25-28}$ Monthly household expenditure for consumption include the following food items (rice, meat and fish, vegetables, cooking oil, granulated sugar), and non-food items (kerosene). For all of the analyses, per capita expenditure was entered as a log-transformed continuous variable to make the distribution more symmetrical and to reduce the effect of any outliers. Per-capita monthly expenditure was categorised to quintiles: q1 (lowest) to q5 (highest).

\section{Statistical analysis}

As the prevalence of multimorbidity varied substantially with age and sex, ${ }^{1}$ we analysed the data stratified by age group ( $40-59$ years and $\geq 60$ years) and separately for men and women. Chronic conditions with prevalence estimates $\geq 1 \%$ were included in estimating multimorbidity prevalence across age groups and sex. The prevalence of multimorbidity was estimated in relation to all sociodemographic correlates. All prevalence measures were direct-standardised to the 2010 age and sex distribution of the Indonesia population (2010 Indonesian Census). ${ }^{29}$ We applied non-parametric tests to test the differences in the mean number of morbidities across different sociodemographic covariates.

The most common clusters of chronic conditions were assessed by clustering the disease types per individual, then reporting the most common (frequencies) within dyads and triads, and also by estimating the prevalence of each cluster within the study population (per 100 persons). Data were reported only for the top 10 frequently occurring combinations of chronic conditions in the sample. Ratios between observed versus expected (multimorbidity coefficients) were also calculated and are reported. ${ }^{30}$ We used the $\chi^{2}$ to test whether the observed prevalence of comorbidity dyad and triad were greater than would be expected if the diseases occurred independently. ${ }^{31}$ Binary logistic regression was used to determine socioeconomic and demographic predictors of multimorbidity compared to zero or one morbid condition. Results are presented in terms of the adjusted
OR (AOR) with 95\% CIs. Multicollinearity for covariates was tested using the variance inflation factor and tolerance values, which were negative. Marginal statistics were computed to estimate the linear prediction of mean number of morbidities and probabilities of multimorbidity across age and sex categories. All analyses were performed using the inverse probability sampling weights. ${ }^{21}$ For analysis involving complete cases only we used inverse probability weighted method and complete cases were weighted by the inverse of their probability of being a complete case. ${ }^{32}$ Data were analysed using Stata software V.12.0 for Windows (StataCorp LP, College Station, Texas, USA) and $p$ values of less than 0.05 were considered statistically significant.

\section{RESULTS}

\section{Participant's characteristics}

Of 11712 participants aged 40 years or above interviewed in the survey, 2014 (17.5\%) did not have complete information related to all chronic diseases and thus they were excluded from further analysis (figure 1). We analysed data from 9438 (51.6\% women) respondents for whom complete information on all included chronic diseases were available. The respondents with complete information were on average 3 years younger than those with incomplete information (54.1 years vs 57.2 years; $\mathrm{p}<0.001)$. Participants with complete information were more likely to be female (AOR: 1.2; 95\% CI 1.1 to 1.4 ), currently married (AOR: $1.3 ; 1.1$ to 1.5 ), high school or above educated (AOR: $1.3 ; 1.2$ to 1.5 ), from a rural area (AOR: $1.1 ; 1.0$ to 1.2 ), and of Javanese ethnicity (AOR: $1.1 ; 1.0$ to 1.3 ). However, respondents with complete information did not differ significantly from those with incomplete information in terms of per capita expenditure. Of those included in the analysis, more than half $(53.5 \%)$ were of Javanese ethnicity, $57.8 \%$ were from rural areas, and $72 \%$ of respondents had attained an elementary level of education or less. Men and women did not differ significantly across different sociodemographic characteristics except for education and marital status (see online supplementary table S1).

\section{Prevalence of chronic conditions and multimorbidity}

Hypertension, hypercholesterolaemia, cardiac diseases and arthritis were the most prevalent chronic morbidities affecting $10 \%-48 \%$ of the population. The distribution of these conditions varied across age and sex group (table 1). The overall prevalence of hypertension, hypercholesterolemia, cardiac diseases and arthritis in women were $52 \%, 20 \%, 14 \%$ and $12 \%$, respectively, compared to $44 \%, 12 \%, 12.7 \%$ and $7.8 \%$, in men. The majority of the chronic morbidities were significantly higher in the older ( $\geq 60$ years) versus younger $(40-59$ years) individuals $(\mathrm{p}<0.05)$.

The mean number of morbidities in the sample was $1.27(\mathrm{SE} \pm 0.01)$ and again varied by age and sex 
Figure 1 IFLS 4 participants and selection of study sample from the original sampled population. CES-D, Centre for Epidemiologic Studies Depression Scale; IFLS-4, Indonesian Family Life Survey.

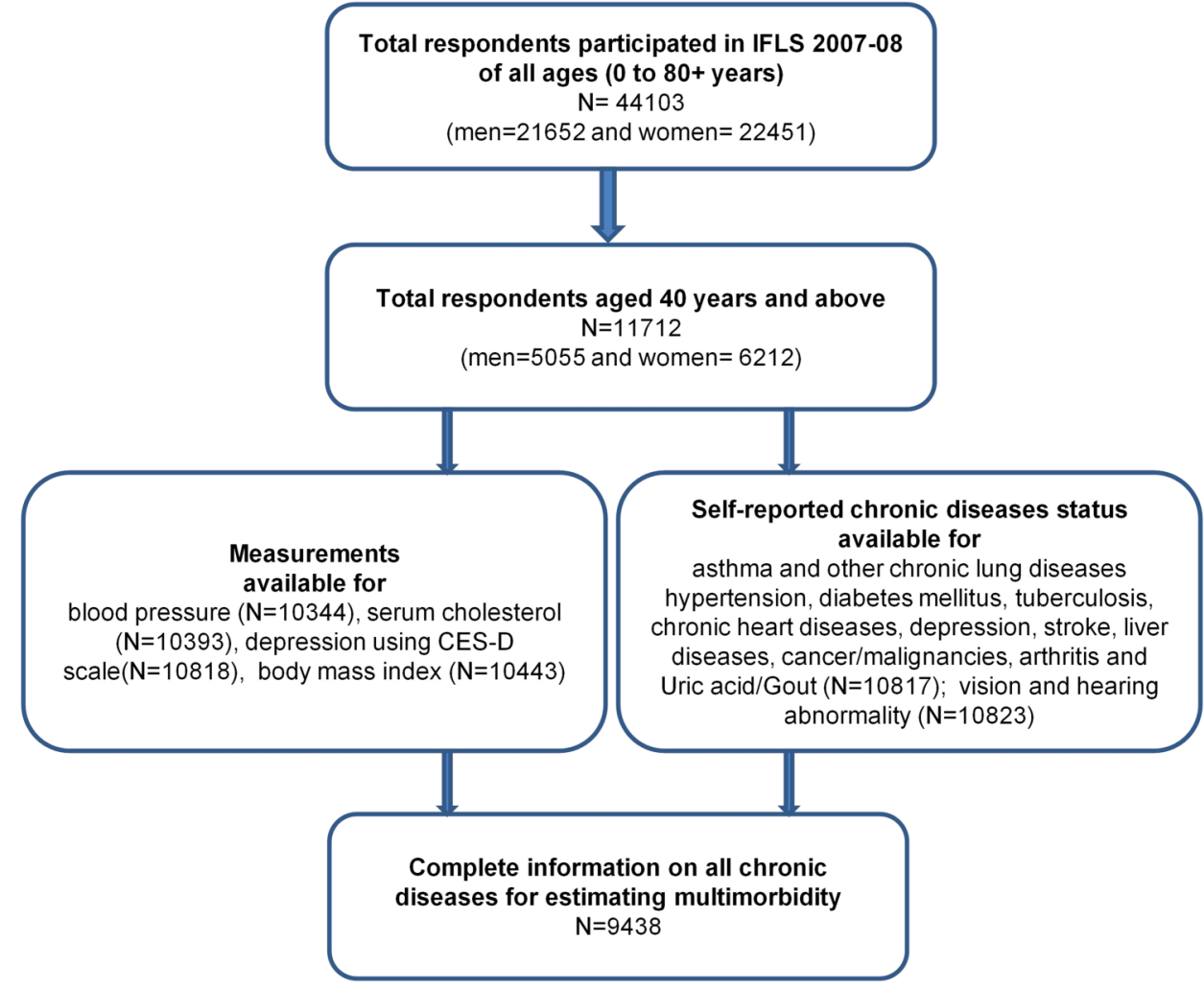

(table 2). Women had significantly higher number of morbidities compared to men $(1.50$ vs $1.15 ; \mathrm{p}<0.001))$. The overall age and sex standardised prevalence of multimorbidity was $35.7 \%$ (95\% CI $34.8 \%$ to $36.7 \%)$ with women having significantly higher prevalence of multimorbidity than men both overall $(41.5 \%$ v $29.5 \%$; $\mathrm{p}<0.001$ ) and at all ages (figure 2 and table 2). Of the people with at least one morbidity, $48.8 \%(47.5 \%$ to $50.1 \%$ ) had multimorbidity. The number of morbidities and the proportion of people with multimorbidity showed a linear trend with increasing age (see online supplementary figure S1); each 5-year increment in age was associated with approximately $20 \%$ greater risk of multimorbidity in men and women. The mean number

Table 1 Age-adjusted weighted prevalence of chronic conditions among Indonesian aged more than 40 years based on IFLS4 survey

\begin{tabular}{|c|c|c|c|c|}
\hline \multirow[b]{2}{*}{ Diseases } & \multicolumn{2}{|c|}{$\begin{array}{l}\text { Age adjusted prevalence } \\
\text { (40-59 years) } \\
\text { Percentage }(95 \% \mathrm{Cl})\end{array}$} & \multicolumn{2}{|c|}{$\begin{array}{l}\text { Age adjusted prevalence } \\
\text { ( }>60 \text { years) } \\
\text { Percentage }(95 \% \mathrm{Cl})\end{array}$} \\
\hline & Men & Women & Men & Women \\
\hline Hypertension & 37.9 (36.1 to 39.7$)$ & 45.8 (44.0 to 47.5$)$ & 58.8 (55.8 to 61.8$)$ & $69.8(67.2$ to 72.5$)$ \\
\hline Hypercholesterolaemia & $12.4(11.2$ to 13.7$)$ & $18.4(17.1$ to 19.8$)$ & 10.5 (8.6 to 12.3$)$ & $23.6(21.2$ to 26.1$)$ \\
\hline Cardiac diseases & 11.1 (9.9 to 12.2$)$ & 13.4 (12.2 to 14.6$)$ & $17.1(14.8$ to 19.4$)$ & $17.8(15.6$ to 19.9$)$ \\
\hline Obesity (BMI $\geq 30$ ) & $5.0(4.2$ to 5.8$)$ & $11.3(10.2$ to 12.4$)$ & $1.5(0.8$ to 2.3$)$ & 4.4 (3.3 to 5.4$)$ \\
\hline Arthritis & $6.0(5.2$ to 6.9$)$ & 10.2 (0.9 to 11.2$)$ & $12.2(10.2$ to 14.1$)$ & $16.6(14.5$ to 18.6$)$ \\
\hline Vision abnormality & 6.7 (5.8 to 7.6$)$ & 6.5 (5.7 to 7.3$)$ & 9.8 (8.1 to 11.5$)$ & 10.5 (8.9 to 12.2$)$ \\
\hline Uric acid/gout & 4.6 (3.9 to 5.4$)$ & $7.2(6.3$ to 8.0$)$ & 6.3 (4.9 to 7.7 ) & $8.4(6.8$ to 10.0$)$ \\
\hline Depression & 4.3 (3.6 to 5.0$)$ & 6.7 (5.8 to 7.5$)$ & 4.4 (3.2 to 5.6$)$ & $8.4(6.8$ to 9.9$)$ \\
\hline Chronic respiratory diseases & 4.1 (3.4 to 4.8$)$ & 3.4 (2.7 to 4.0$)$ & 9.5 (7.7 to 11.2$)$ & 4.3 (3.2 to 5.5$)$ \\
\hline Diabetes mellitus & 3.8 (3.0 to 4.4$)$ & 4.2 (3.5 to 4.8$)$ & 5.2 (3.9 to 6.5$)$ & 4.4 (3.3 to 5.5$)$ \\
\hline Hearing problem & 0.7 (0.4 to 1.0$)$ & $0.6(0.3$ to 0.8$)$ & $2.0(1.2$ to 2.8$)$ & 2.6 (1.7 to 3.5$)$ \\
\hline Stroke & $0.3(0.1$ to 0.5$)$ & 1.0 (0.6 to 1.3$)$ & 2.1 (1.2 to 2.9$)$ & 1.1 (0.5 to 1.7$)$ \\
\hline Liver diseases & 0.9 (0.6 to 1.3$)$ & 0.7 (0.4 to 0.9$)$ & 0.7 (0.2 to 1.3$)$ & 0.1 (0.0 to 0.2$)$ \\
\hline Tuberculosis & 0.6 (0.3 to 0.8$)$ & $0.3(0.1$ to 0.5$)$ & $0.6(0.2$ to 1.0$)$ & 0.3 (0.0 to 0.5$)$ \\
\hline Cancer & 0.1 (0.0 to 0.3$)$ & $0.7(0.4$ to 1.0$)$ & $0.2(0.0$ to 0.4$)$ & 0.7 (0.2 to 1.3) \\
\hline
\end{tabular}

BMI, body mass index; IFLS-4, Indonesian Family Life Survey. 
Figure 2 The proportion of population with number of chronic condition or morbidities according to age groups and gender.
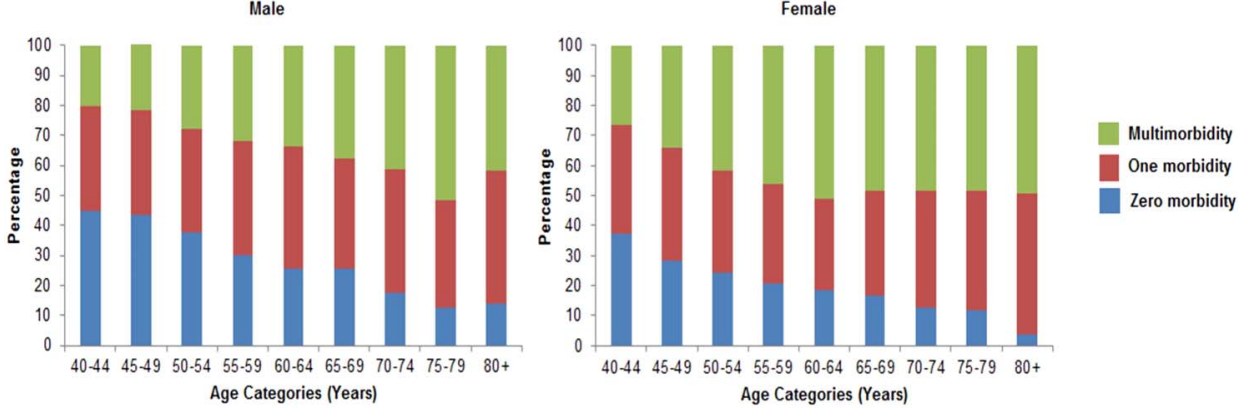

of chronic conditions was significantly higher in people of non-Javanese ethnicity (1.37 vs 1.27 ; $\mathrm{p}=<0.001)$ compared with Javanese ethnicity, who lived in urban compared with rural areas ( 1.48 vs $1.17 ; \mathrm{p}<0.001)$, who had the highest per capita expenditure versus the lowest $(\mathrm{p}<0.001)$, and with educational attainment $(\mathrm{p}$ for trend $<0.001)$.

Table 3 shows the results of multivariable multinomial logistic regression of factors associated with multimorbidity. Increasing age, female gender, non-Javanese ethnicity and high per-capital expenditure were all significantly associated with higher odds of multimorbidity. Higher education status was significantly correlated with higher odds of multimorbidity but only in men. Women younger than 70 years of age had significantly higher odds of multimorbidity relative to men (figure 3 ).

\section{Common multimorbidity combinations}

Figure 4 presents the leading five most frequently occurring morbidity dyads and triads among respondents with multimorbidity. The details of observed and expected prevalence rates for these combinations and multimorbidity coefficients (observed/expected ratio) are presented in the appendix (see online supplementary tables S2-S5). Most of the disease combinations were identified as the most prevalent conditions in table 1 . The combination of hypertension with cardiac diseases, hypercholesterolaemia, arthritis and uric acid/gout were the most commonly occurring dyads in both sexes. The majority of these combinations showed statistically significantly higher observed prevalence than would be expected at random. The most prevalent individual disease conditions such as hypertension, hypercholesterolaemia, prevalent cardiac diseases and arthritis dominated the most frequent triad combinations. These four conditions, together with diabetes mellitus, uric acid/ gout, chronic respiratory diseases, obesity and vision abnormalities, were the main components of the 10 most prevalent triads across age groups with minimal differences between the sexes.

\section{DISCUSSION}

This study is the first to report on the population prevalence of multimorbidity in the Indonesian adult population using subnational data from the Indonesia Family Life Survey (IFLS-4). More than a third of adults over 40 years of age and half of individuals above 60 years had multimorbidity, but the pattern varied markedly across different sociodemographic characteristics. Increasing age, female gender, high per-capita household expenditure and urban locality were significant predictors of multimorbidity status.

In the current study, the prevalence of hypertension as well as self-reported cardiac diseases and diabetes was comparable with previous estimates that have been reported using nationally representative data. ${ }^{33-37}$ The prevalence of obesity was, however, lower than in earlier reports although this is likely to be due in part to the lower cut-point for BMI used to define obesity in those studies. ${ }^{37}$ With respect to the prevalence of other major chronic conditions including hypertension, hypercholesterolaemia and diabetes our findings are comparable with age and sex specific prevalence estimates reported in geographically and economically similar Asian countries such as Malaysia, Thailand and the Philippines. ${ }^{38}$

Our findings demonstrate that the most commonly occurring comorbidities, were hypertension, prevalent cardiac diseases, arthritis, and hypercholesterolaemia together with vision abnormality and obesity. Similar combinations of prevalent cardiometabolic morbidities have also been reported by the recent systematic-reviews. ${ }^{39}$ Stratifying the population by age and sex did not materially alter our results, although some interesting patterns were noted. For example, the most frequently occurring dyad (which comprised hypertension and hypercholesterolaemia) occurred with a frequency of $11 \%$ indicating that there is no dominant combination of morbid conditions that affects the population. From a public health perspective, this is challenging and requires development of comprehensive and contextualised clinical practice guidelines offering clinical management and treatment decision support for patients with multiple chronic diseases. ${ }^{40}$

It is difficult to directly compare our findings with those from previous studies due to differences in study methodology including in how multimorbidity was defined $^{7}{ }^{31}$ However, systematic reviews of studies have indicated a prevalence rate of multimorbidity ranging from less than $5 \%$ to more than $90 \%$, with notable 
Table 2 Age-adjusted mean number of chronic condition (SE) and prevalence of multimorbidity across different sociodemographic covariates ( $\mathrm{N}=9438$ )

\begin{tabular}{|c|c|c|c|c|c|c|c|c|c|}
\hline \multirow[b]{3}{*}{$\begin{array}{l}\text { Sociodemographic } \\
\text { characteristics }\end{array}$} & \multirow[b]{3}{*}{$\begin{array}{l}\text { Weighted } \\
\% \text { of } \\
\text { sample }\end{array}$} & \multicolumn{4}{|l|}{ 40-60 years } & \multicolumn{4}{|c|}{ More than 60 years } \\
\hline & & \multicolumn{2}{|l|}{ Men } & \multicolumn{2}{|l|}{ Women } & \multicolumn{2}{|l|}{ Men } & \multicolumn{2}{|l|}{ Women } \\
\hline & & $\begin{array}{l}\text { Mean } \\
\text { number of } \\
\text { morbidities } \\
\text { (SE) }\end{array}$ & $\begin{array}{l}\text { Prevalence \% } \\
(95 \% \mathrm{Cl})\end{array}$ & $\begin{array}{l}\text { Mean } \\
\text { number of } \\
\text { morbidities } \\
\text { (SE) }\end{array}$ & $\begin{array}{l}\text { Prevalence \% } \\
(95 \% \mathrm{Cl})\end{array}$ & $\begin{array}{l}\text { Mean } \\
\text { number of } \\
\text { morbidities } \\
\text { (SE) }\end{array}$ & $\begin{array}{l}\text { Prevalence \% } \\
(95 \% \mathrm{Cl})\end{array}$ & $\begin{array}{l}\text { Mean } \\
\text { number of } \\
\text { morbidities } \\
\text { (SE) }\end{array}$ & $\begin{array}{l}\text { Prevalence \% } \\
(95 \% \mathrm{Cl})\end{array}$ \\
\hline \multicolumn{10}{|l|}{ Location } \\
\hline Rural & 57.8 & $0.8(0.02)$ & 21.0 (18.9 to 23.1$)$ & $1.2(0.02)$ & 30.8 (28.5 to 33.1$)$ & $1.3(0.04)$ & 33.7 (29.9 to 37.5 ) & $1.6(0.05)$ & 43.9 (40.0 to 47.8$)$ \\
\hline Urban & 42.2 & $1.1(0.02)$ & 29.1 (26.7 to 31.5) & $1.5(0.03)$ & 41.1 (38.7 to 43.5 ) & $1.7(0.06)$ & 47.4 (43.0 to 51.9$)$ & $2.0(0.06)$ & 58.3 (54.3 to 62.3$)$ \\
\hline \multicolumn{10}{|l|}{ Ethnicity } \\
\hline Javanese & 53.5 & $0.9(0.02)$ & 21.9 (19.7 to 24.0$)$ & $1.3(0.02)$ & 33.5 (31.1 to 35.9 ) & $1.3(0.05)$ & 0.3 (30.7 to 38.9 ) & $1.7(0.05)$ & 48.2 (44.1 to 52.3 ) \\
\hline Non-Javanese & 46.5 & $1.0(0.02)$ & 27.7 (25.4 to 30.0$)$ & $1.4(0.30)$ & 37.6 (35.2 to 40.0$)$ & $1.5(0.05)$ & 43.3 (39.1 to 47.4$)$ & $1.7(0.05)$ & 50.8 (46.7 to 54.8 ) \\
\hline \multicolumn{10}{|l|}{ Education } \\
\hline $\begin{array}{l}\text { Elementary } \\
\text { education or less }\end{array}$ & 71.6 & $0.9(0.02)$ & 20.7 (18.7 to 22.7 ) & $1.3(0.02)$ & 33.7 (31.7 to 35.6 ) & $1.3(0.04)$ & 35.0 (31.8 to 38.3$)$ & $1.7(0.04)$ & 48.0 (45.0 to 51.1$)$ \\
\hline High school & 22.2 & $1.1(0.03)$ & 28.3 (25.3 to 31.2 ) & $1.5(0.04)$ & 41.1 (37.8 to 44.7 ) & $1.7(0.08)$ & 51.8 (44.9 to 58.7 ) & $2.2(0.15)$ & 62.4 (53.3 to 71.6$)$ \\
\hline $\begin{array}{l}\text { Graduate and } \\
\text { above }\end{array}$ & 6.1 & $1.3(0.07)$ & 35.9 (30.3 to 41.5$)$ & $1.6(0.08)$ & 47.6 (40.8 to 54.5$)$ & $2.0(0.21)$ & 58.7 (44.5 to 72.9$)$ & $3.0(0.52)$ & 76.8 (63.6 to 90.0$)$ \\
\hline \multicolumn{10}{|l|}{ Marital status } \\
\hline Currently married & 81.0 & $1.0(0.02)$ & 24.6 (23.0 to 26.2 ) & $1.3(0.02)$ & 34.9 (33.0 to 36.8 ) & $1.4(0.03)$ & 37.9 (34.8 to 41.0$)$ & $1.7(0.07)$ & 46.6 (41.6 to 51.6$)$ \\
\hline $\begin{array}{l}\text { Currently not } \\
\text { married }\end{array}$ & 19.0 & $0.9(0.07)$ & 23.0 (16.2 to 29.9$)$ & $1.3(0.04)$ & 36.4 (32.5 to 40.3$)$ & $1.8(0.12)$ & 45.0 (36.0 to 54.0$)$ & $1.8(0.04)$ & $51.0(47.3$ to 54.8$)$ \\
\hline \multicolumn{10}{|l|}{ Per capita expenditure } \\
\hline Q1 (lowest) & 22.9 & $0.7(0.03)$ & 15.5 (12.4 to 18.5$)$ & $1.0(0.04)$ & 28.3 (24.7 to 31.9$)$ & $1.2(0.06)$ & 29.9 (24.3 to 35.5$)$ & $1.5(0.07)$ & 41.2 (35.3 to 47.0$)$ \\
\hline Q2 & 21.0 & $0.9(0.04)$ & 23.3 (19.8 to 26.9 ) & $1.2(0.04)$ & 29.7 (26.0 to 33.3) & $1.2(0.07)$ & 31.7 (25.8 to 37.7 ) & $1.7(0.08)$ & 47.7 (41.3 to 54.2$)$ \\
\hline Q3 & 20.6 & $1.0(0.04)$ & 24.7 (21.2 to 28.1$)$ & $1.3(0.04)$ & 35.1 (31.4 to 38.7$)$ & $1.4(0.08)$ & 37.1 (30.9 to 43.4 ) & $1.7(0.08)$ & $50.0(43.5$ to 56.4$)$ \\
\hline Q4 & 19.7 & $1.0(0.04)$ & 26.0 (22.3 to 29.6$)$ & $1.4(0.05)$ & 39.1 (35.5 to 42.8 ) & $1.6(0.08)$ & 47.3 (40.2 to 54.4$)$ & $1.8(0.08)$ & 51.7 (45.2 to 58.2$)$ \\
\hline Q5 (highest) & 15.6 & $1.3(0.05)$ & $34.0(29.9$ to 38.1$)$ & $1.6(0.05)$ & 46.6 (42.6 to 50.7$)$ & $1.8(0.09)$ & 58.7 (50.9 to 66.6$)$ & $2.2(0.11)$ & $61.2(54.1$ to 68.4$)$ \\
\hline Overall $^{*}$ & & $1.0(0.01)$ & 24.6 (23.0 to 26.1$)$ & $1.3(0.02)$ & 35.4 (33.8 to 37.1$)$ & $1.4(0.03)$ & 38.7 (35.8 to 41.7 ) & $1.7(0.04)$ & 49.4 (46.5 to 52.3 ) \\
\hline
\end{tabular}


Table 3 Multivariable analysis of the association between sociodemographic characteristics and multimorbidity in Indonesian population

\begin{tabular}{|c|c|c|}
\hline \multirow{2}{*}{$\begin{array}{l}\text { Sociodemographic } \\
\text { characteristics }\end{array}$} & \multicolumn{2}{|c|}{ Adjusted OR (95\% Cl) } \\
\hline & Men & Women \\
\hline \multicolumn{3}{|l|}{ Age (years) } \\
\hline $40-49$ & 1.0 & 1.0 \\
\hline $50-59$ & $1.6(1.3$ to 1.9$)$ & $1.7(1.5$ to 2.0$)$ \\
\hline $60-69$ & $2.3(1.8$ to 2.8$)$ & $2.4(2.0$ to 2.9$)$ \\
\hline $70+$ & 3.6 (2.8 to 4.6$)$ & 2.3 (1.7 to 2.9$)$ \\
\hline \multicolumn{3}{|l|}{ Housing location } \\
\hline Rural & 1.0 & 1.0 \\
\hline Urban & 1.3 (1.1 to 1.5$)$ & $1.4(1.3$ to 1.6$)$ \\
\hline \multicolumn{3}{|l|}{ Ethnicity } \\
\hline Javanese & 1.0 & 1.00 \\
\hline Non-Javanese & $1.4(1.1$ to 1.5$)$ & 1.1 (1.1 to 1.3$)$ \\
\hline \multicolumn{3}{|l|}{ Education } \\
\hline $\begin{array}{l}\text { Elementary education } \\
\text { or less }\end{array}$ & 1.0 & 1.0 \\
\hline High school & $1.2(1.0$ to 1.5$)$ & 1.0 (0.9 to 1.2$)$ \\
\hline Graduate and above & 1.5 (1.1 to 1.9$)$ & $1.2(0.9$ to 1.5$)$ \\
\hline \multicolumn{3}{|l|}{ Marital status } \\
\hline Currently married & 1.0 & 1.0 \\
\hline Currently not married & $1.1(0.8$ to 1.4$)$ & 1.1 (0.9 to 1.2$)$ \\
\hline \multicolumn{3}{|c|}{ Per capita expenditure quintiles } \\
\hline Q1 (lowest) & 1.00 & 1.0 \\
\hline Q2 & $1.3(1.1$ to 1.7$)$ & 1.1 (0.9 to 1.3$)$ \\
\hline Q3 & $1.5(1.2$ to 1.9$)$ & 1.3 (1.1 to 1.6$)$ \\
\hline Q4 & $1.7(1.3$ to 2.1$)$ & 1.5 (1.2 to 1.8$)$ \\
\hline Q5 (highest) & 2.2 (1.6 to 2.9$)$ & 1.8 (1.5 to 2.3$)$ \\
\hline
\end{tabular}

differences across different age groups and study settings. ${ }^{7}$ A recent study analysing data from six lowerincome and middle-income countries also reported the multimorbidity prevalence to range from about
4-34\%. ${ }^{42}$ In line with earlier studies, we observed the prevalence of multimorbidity to increase with age and was higher among those living in urban areas. ${ }^{1} 71442-44$ However, due to the age distribution of the population the absolute burden of multimorbidity was greater among those under 60 years of age in whom two-thirds had the condition, consistent with previous observations that multimorbidity represents a significant health challenge to younger as well as older populations. ${ }^{45}$

In agreement with previous studies, ${ }^{1}{ }^{2} \quad 164243$ we observed women to be more vulnerable to multimorbidity compared to men. And as in other lower-income and middle-income countries undergoing an epidemiological transition, ${ }^{46}$ the prevalence of multimorbidity increased with greater affluence which is in contrast to the situation in higher-income countries where the least economically advantaged are typically at greatest risk of multimorbidity. ${ }^{1} 141542$ It is possible, however, that this discrepancy may be explained by respondents from lower socioeconomic background being less likely to report their health condition either due to limited access to healthcare or under diagnosis. ${ }^{47}$ We also observed people of Javanese ethnicity to have a lower prevalence of multimorbidity compared to other ethnicities which may reflect differences in socioeconomic position.

A major strength of this study was the large randomly selected representative sample of Indonesian population which allows for greater generalisation of results. Population-based prevalence estimates of multimorbidity are essential for understanding the true health status of the community. However, there are some significant study limitations. The cross-sectional nature of the study did not permit any causal inferences to be made. We may have underestimated the prevalence of multimorbidity, since only 15 chronic conditions were included in
Figure 3 Marginal plots showing relative OR for each category of age and sex compared to 40-44 years male participants, adjusted for other socio-demographic variables.

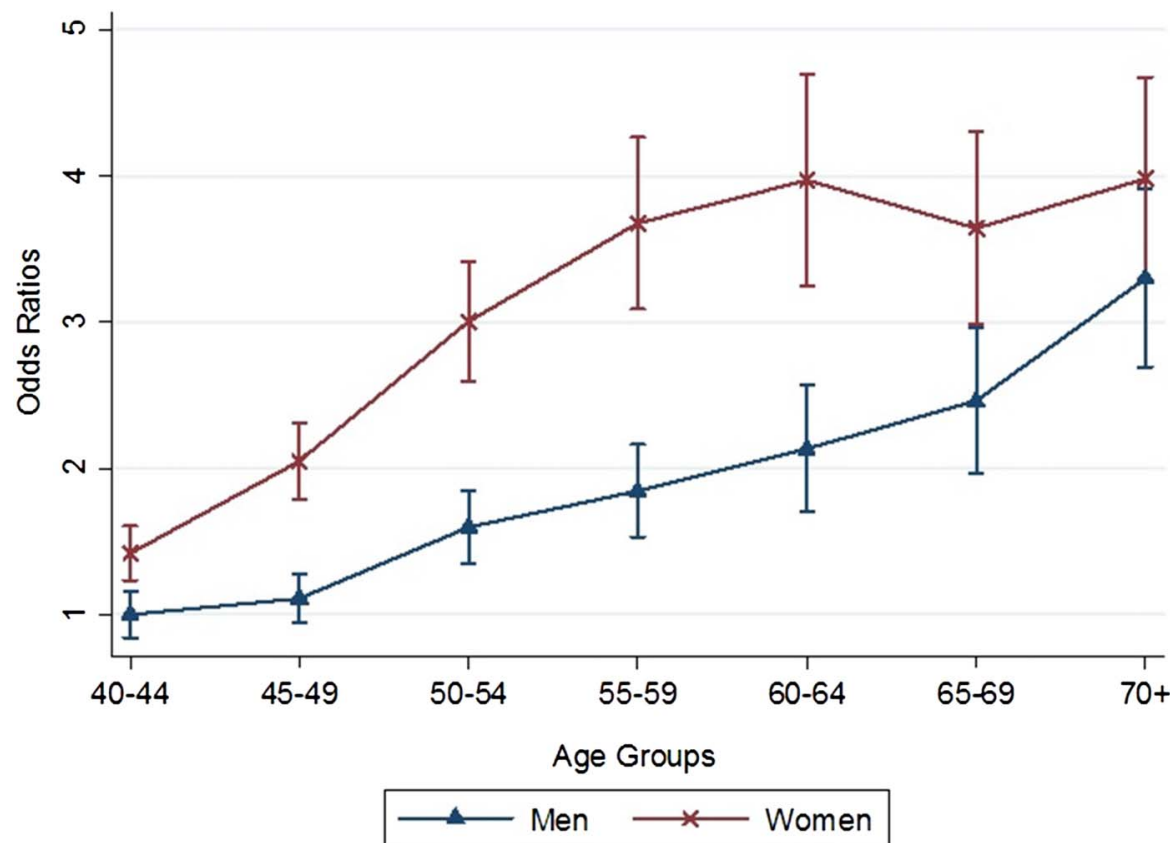




\begin{tabular}{lll} 
Order & Men & Women \\
\hline & Disease dyads & \\
\hline 1 & Hypertension- Cardiac Diseases & Hypertension-Hypercholesterolemia \\
2 & Hypertension-Hypercholesterolemia & Hypertension-Cardiac Diseases \\
3 & Hypertension-Arthritis & $\begin{array}{l}\text { Hypertension-Arthritis } \\
\text { Hypertension-Obesity }\end{array}$ \\
4 & Hypertension-Vision abnormality & Hypertension-Uric acid/Gout \\
\hline & Hypertension-Uric acid/Gout & \\
\hline 1 & Disease triads & Hypertension-Cardiac Diseases-Arthritis \\
2 & Hypertension-Cardiac Diseases-Arthritis & Hypertension-Arthritis-Uric acid/Gout \\
3 & Hypertension-Arthritis-Uric acid/Gout & Hypertension-Hypercholesterolemia-Arthritis \\
4 & Hypertension-Cardiac Diseases-Chronic respiratory diseases & Hypertension-Hypercholesterolemia-Cardiac Diseases \\
5 & Hypertension-Cardiac Diseases-Diabetes mellitus & Hypertension-Arthritis-Vision abnormality \\
\hline
\end{tabular}

Details of frequency and prevalence of individual combinations of chronic conditions according to-age- and sex-group are presented in supplementary table 2 to table 5 .

Figure 4 Leading five most commonly occurring combinations of chronic conditions among male and female with multimorbidity.

the survey and the outcome was based on self-report, which may have introduced some misclassification bias. Nevertheless, this type of misclassification is likely to have been at random. We performed a complete case analysis which has the potential to introduce attrition bias if the excluded individuals are systematically different from those included. However, we used inverse probability weighted method to directly analyse only the complete cases with special weights assigned to those cases based on estimated probabilities of completeness, thereby minimising the possibility of attrition bias. ${ }^{32} 48$ Moreover, the proportion of missing data was small and the prevalence of individual diseases did not vary significantly across participants with complete and incomplete information. The measure of multimorbidity was only concerned with the number of diseases and did not take into consideration the intensity or severity of disease nor did it take into account any undiagnosed chronic ailment. Moreover, the present study included obesity as a chronic condition, which has been previously been considered to be only a risk factor for multimorbidity, rather than a disease entity. ${ }^{49-51}$ However, recent systematic reviews have shown obesity to be an independent predictor of patterns of multimorbidity, thereby creating an evidence-base for obesity to be included as a morbid condition. ${ }^{13}{ }^{52}$ Lastly, we used observed-to-expected ratios to analyse multimorbidity pattern, which apart from the technical difficulties implicit to the extraordinary numbers of theoretically possible combinations of diseases, depend on the prevalence of the individual diseases and do not adequately adjust for chance multimorbidity when non-random multimorbidity exists. ${ }^{39}$

In summary, multimorbidity affects more than one-third of the Indonesian adult population with a greater absolute burden occurring in younger individuals and in women. Hypertension was almost integral to all patterns of multimorbidity at all ages indicating that effective interventions to reduce mean population BP should be given high priority in the Indonesian population. The recent comprehensive review on health system issues on managing non-communicable diseases (NCD) in the Asia-Pacific region highlighted a shortage of adequately trained health workers to manage NCDs; a lack of investment in training in the management of chronic diseases; weak health information systems that lack integrated and coordinated collection of data on chronic diseases; and unsuitable service delivery models for the continuum of care required for chronic diseases. ${ }^{53}$

A comprehensive generalist care approach that is mainly, but not exclusive to primary care, has been suggested to be the most suitable strategy for the management of patients with multimorbidity. ${ }^{1}{ }^{44}$ However, the delivery of primary healthcare in Indonesia is principally built around the management of single diseases and therefore a greater focus on the development of contextualised treatment protocols for the management of comorbid conditions is needed. Indonesia has adopted the WHO Package of essential non-communicable disease interventions (WHO PEN) for primary healthcare in lowresource settings. ${ }^{54}$ However, it is still at an early stage of implementation and requires scaling-up at the national level. Given the paucity of data on the predictors and patterns of multimorbidity in low and middle income countries, ${ }^{13}{ }^{41}$ findings from the current study are timely and provide novel insights into the burden of multimorbidity in these countries. However, further research is needed to understand how multimorbidity impacts healthcare utilisation and healthcare costs particularly in these low-resource settings.

Acknowledgements The research was conducted based on IFLS-4 conducted by RAND (http://www.rand.org/labor/FLS/IFLS.html). The authors thank RAND for providing the access to the survey data. The authors are grateful to the study participants who participated in the survey.

Contributors MAH, AAM and RRH conceived the study. MAH was guided by supervisors AAM and RRH on statistical analysis, interpretation of findings, and drafting of the manuscript. AAM and RRH provided critical inputs in revising the manuscript. All authors read and approved the final manuscript.

Funding MAH is funded by International Postgraduate Research Scholarship (IPRS) and UQ-Centennial scholarship (Student number- 43253849). 
Competing interests None declared.

Ethics approval The IFLS data set used for this research, the confidentiality and anonymity of the names, addresses, locations and neighbourhoods of the study participants was kept by the data source. Under the RAND human subjects protection rules, respondents participating in the survey were given an assurance that their answers were confidential and that their identity would not be revealed to anyone other than through an anonymous code. The use of the data set for this study has also been approved by the Medical Research Ethics Committee (MREC), School of Public Health, The University of Queensland.

Provenance and peer review Not commissioned; externally peer reviewed.

Data sharing statement No additional data are available.

Open Access This is an Open Access article distributed in accordance with the Creative Commons Attribution Non Commercial (CC BY-NC 4.0) license, which permits others to distribute, remix, adapt, build upon this work noncommercially, and license their derivative works on different terms, provided the original work is properly cited and the use is non-commercial. See: http:// creativecommons.org/licenses/by-nc/4.0/

\section{REFERENCES}

1. Barnett K, Mercer SW, Norbury M, et al. Epidemiology of multimorbidity and implications for health care, research, and medical education: a cross-sectional study. Lancet 2012;380:37-43.

2. Fortin M, Bravo G, Hudon C, et al. Prevalence of multimorbidity among adults seen in family practice. Ann Fam Med 2005;3:223-8.

3. Salisbury C. Multimorbidity: redesigning health care for people who use it. Lancet 2012;380:7-9.

4. Walker A. Multiple chronic diseases and quality of life: patterns emerging from a large national sample, Australia. Chronic IIIn 2007;3:202-18.

5. Boyd CM, Fortin M. Future of multimorbidity research: how should understanding of multimorbidity inform health system design? Public Health Rev 2010;32:451-74.

6. Bahler C, Huber CA, Brungger B, et al. Multimorbidity, health care utilization and costs in an elderly community-dwelling population: a claims data based observational study. BMC Health Serv Res 2015;15:23.

7. Fortin M, Stewart M, Poitras M-E, et al. A systematic review of prevalence studies on multimorbidity: toward a more uniform methodology. Ann Fam Med 2012;10:142-51.

8. Glynn LG, Valderas JM, Healy P, et al. The prevalence of multimorbidity in primary care and its effect on health care utilization and cost. Fam Pract 2011;28:516-23.

9. Wolff JL, Starfield B, Anderson G. Prevalence, expenditures, and complications of multiple chronic conditions in the elderly. Arch Intern Med 2002;162:2269-76.

10. Gijsen R, Hoeymans N, Schellevis F, et al. Causes and consequences of comorbidity: a review. J Clin Epidemiol 2001:54:661-74.

11. Pati S, Swain S, Hussain MA, et al. Prevalence, correlates, and outcomes of multimorbidity among patients attending primary care in Odisha, India. Ann Fam Med 2015;13:446-50.

12. Marengoni A, Onder G. Guidelines, polypharmacy, and drug-drug interactions in patients with multimorbidity. BMJ 2015;350:h1059.

13. Violan C, Foguet-Boreu Q, Flores-Mateo G, et al. Prevalence, determinants and patterns of multimorbidity in primary care: a systematic review of observational studies. PLOS ONE 2014;9: e102149.

14. Alaba O, Chola L. The social determinants of multimorbidity in South Africa. Int J Equity Health 2013;12:63.

15. Pati S, Agrawal S, Swain S, et al. Non communicable disease multimorbidity and associated health care utilization and expenditures in India: cross-sectional study. BMC Health Serv Res 2014;14:451.

16. Khanam MA, Streatfield PK, Kabir ZN, et al. Prevalence and patterns of multimorbidity among elderly people in rural Bangladesh: a cross-sectional study. J Health Popul Nutr 2011;29:406-14.

17. Nimako BA, Baiden F, Sackey SO, et al. Multimorbidity of chronic diseases among adult patients presenting to an inner-city clinic in Ghana. Global Health 2013;9:61.

18. World Health Organization. Country statistics and global health estimates by WHO and UN patrners. Indonesia country profile January. 2015. http://www.who.int/gho/countries/idn.pdf?ua=1 (accessed 20 Aug 2015)
19. Badan Penelitian Dan Pengembangan Kesehatan. Kementerian Kesehatan. Republik Indonesia. Riset Kesehatan Dasar (RISKESDAS) 2013, Laporan Nasional 2013. Available at : http:// www.depkes.go.id/resources/download/general/Hasil\%20Riskesdas \%202013.pdf (accessed 25 Nov 2015).

20. Maharani A, Tampubolon G. Unmet needs for cardiovascular care in Indonesia. PLOS ONE 2014;9:e105831.

21. Strauss J, Witoelar F, Sikoki B, et al. The Fourth wave of Indonesian Family Life Survey (IFLS4): Overview and Field Report. RAND, April 2009.

22. Finkelstein EA, Chay J, Bajpai S. The economic burden of self-reported and undiagnosed cardiovascular diseases and diabetes on Indonesian households. PLOS ONE 2014;9: e99572.

23. SCIRE Project. Center for Epidemiological Studies Depression Scale (CES-D and CES-D-10). Secondary SCIRE Project. Center for Epidemiological Studies Depression Scale (CES-D and CES-D-10) Feb 1, 2013. 2010. http://www.scireproject.com/outcome-measuresnew/center-epidemiological-studies-depression-scale-ces-d-and-ces -d-10\#

24. Chobanian AV, Bakris GL, Black HR, et al. The seventh report of the Joint National Committee on prevention, detection, evaluation, and treatment of high blood pressure: the JNC 7 report. JAMA 2003;289:2560-72.

25. Christiani Y, Byles J, Tavener M, et al. Socioeconomic related inequality in depression among young and middle-adult women in Indonesias major cities. J Affect Disord 2015;182:76-81.

26. O'Donnell O, Doorslaer EV, Wagstaff A, et al. Analyzing health equity using household survey data a guide to techniques and their implementation: Washington DC. The World Bank, 2008.

27. Lindelow M. Sometimes more equal than others: how health inequalities depend on the choice of welfare indicator. Health Econ 2006;15:263-79.

28. Chuma J, Molyneux C. Estimating inequalities in ownership of insecticide treated nets: does the choice of socio-economic status measure matter? Health Policy Plan 2009 ;24:83-93.

29. Statistics Indonesia, 2010 Population Census Data Secondary Statistics Indonesia, 2010 Population Census Data. http://sp2010. bps.go.id/index.php/navigation/topik (accessed 20 Apr 2015).

30. Formiga F, Ferrer A, Sanz H, et al. Patterns of comorbidity and multimorbidity in the oldest old: the Octabaix study. Eur J Intern Med 2013;24:40-4.

31. Van den Akker M, Buntinx F, Roos S, et al. Problems in determining occurrence rates of multimorbidity. J Clin Epidemiol 2001;54:675-9.

32. Seaman SR, White IR. Review of inverse probability weighting for dealing with missing data. Stat Methods Med Res 2013;22: 278-95.

33. Soemantri S, Pradono J, Hapsari D. SURKESNAS 2001. National Household Health Survey Morbidity Study-NCD Risk Factors In Indonesia. 2001. Available at http://www.who.int/chp/steps/STEPS Report_Indonesia_National_2001.pdf (accessed on 25 Nov 2015).

34. Susilowati D, Aryastami NK, Erry E. Hypertensi dan faktor-faktor risikonya di Indoensia. Bull Health Syst Res 2010;13:123-31.

35. Handayani L, Maryani $H$, Suharmiati D. Analisis hubungan penyakit Jantung dengan faktor fisiologis abnormal Kajian Data Riskesdas 2007 sebagai Upaya Pencegahan Tingkat Individu terhadap Kematian Akibat Penyakit Jantung. Buletin Penelitian Sistem Kesehatan 2009;12:133-43.

36. Sumartono W, Sirait AM, Holy M, et al. Smoking and sociodemographic determinant of cardiovascular diseases among males $45+$ years in Indonesia. Int J Environ Res Public Health 2011;8:528-39.

37. The National Institute of Health Research and Development. Ministry of Health. Republic of Indonesia. Result of National Basic Health Research (RISKESDAS 2007). 2008. Available at http:// biofarmaka.ipb.ac.id/biofarmaka/2014/Riskesdas2007\%20-\% 20Report\%20on\%20Result\%20of\%20National\%20Basic\%20Health $\% 20$ Research.pdf (accessed 25 Nov 2015).

38. Huxley RR, Hirakawa Y, Hussain MA, et al. Age- and sex-specific burden of cardiovascular disease attributable to 5 major and modifiable risk factors in 10 Asian countries of the Western Pacific Region. Circ J 2015;79:1662-74.

39. Prados-Torres A, Calderón-Larrañaga A, Hancco-Saavedra J, et al. Multimorbidity patterns: a systematic review. J Clin Epidemiol 2014;67:254-66.

40. Muth C, van den Akker M, Blom J, et al. The Ariadne principles: how to handle multimorbidity in primary care consultations. BMC Med 2014;12:223.

41. Pati S, Swain S, Hussain MA, et al. Prevalence and outcomes of multimorbidity in South Asia: a systematic review. BMJ Open 2015;5:e007235. 
42. Lee JT, Hamid F, Pati S, et al. Impact of noncommunicable disease multimorbidity on healthcare utilisation and out-of-pocket expenditures in middle-income countries: cross sectional analysis. PLOS ONE 2015;10:e0127199.

43. Agborsangaya $\mathrm{C}$, Lau $\mathrm{D}$, Lahtinen $\mathrm{M}$, et al. Multimorbidity prevalence and patterns across socioeconomic determinants: a cross-sectional survey. BMC Public Health 2012;12:201.

44. Salisbury C, Johnson L, Purdy S, et al. Epidemiology and impact of multimorbidity in primary care: a retrospective cohort study. $\mathrm{Br} J$ Gen Pract 2011;61:e12-21.

45. Taylor AW, Price K, Gill TK, et al. Multimorbidity-not just an older person's issue. Results from an Australian biomedical study. BMC Public Health 2010;10:718.

46. Pearson TA. Education and income: double-edged swords in the epidemiologic transition of cardiovascular disease. Ethn Dis 2003;13 (2 Suppl 2):S158-63.

47. Vellakkal S, Subramanian SV, Millett C, et al. Socioeconomic inequalities in non-communicable diseases prevalence in India: disparities between self-reported diagnoses and standardized measures. PLOS ONE 2013;8:e68219.

48. Greenland S, Rothman KJ. Fundamrentals of epidemiologic data analysis. In: Rothman KJ, Greenland S, Lash TL, eds. Modern epidemiology. Philadelphia, PA, USA: LIppincott Williams \& Wilkins, 2008:219.

49. Fortin M, Haggerty J, Almirall J, et al. Lifestyle factors and multimorbidity: a cross sectional study. BMC Public Health 2014;14:686.

50. Booth HP, Prevost AT, Gulliford MC. Impact of body mass index on prevalence of multimorbidity in primary care: cohort study. Fam Pract 2014;31:38-43.

51. Agborsangaya C, Ngwakongnwi E, Lahtinen M, et al. Multimorbidity prevalence in the general population: the role of obesity in chronic disease clustering. BMC Public Health 2013;13:1161.

52. Prados-Torres A, Poblador-Plou B, Calderón-Larrañaga A, et al. Multimorbidity patterns in primary care: interactions among chronic diseases using factor analysis. PLoS ONE 2012;7:e32190.

53. Abdullah A, Mannava $P$, Annear P. Non-communicable diseases and health systems in the Asia-Pacific region: a review of the literature. Melbourne: Nossal Institute for Global Health, 2013. http:// ni.unimelb.edu.au/non_communicable_diseases/? $a=772319$ (accessed on 2 Nov 2015).

54. World Health Organization. Package of essential noncommunicable (PEN) disease interventions for primary health care in low-resource settings. 2010. http://www.who.int/nmh/publications/essential_ncd_ interventions_Ir_settings.pdf (accessed 2 Nov 2015). 